\title{
Cyberbullying in YouTube: The Role of Psychological Loneliness Towards the Emotional Regulation
}

\author{
Shalmarona Shalmarona ${ }^{1}$ Jessica Chandhika ${ }^{1 *}$ Naomi Soetikno ${ }^{1}$ \\ ${ }^{1}$ Faculty of Psychology, Universitas Tarumanagara, Jakarta, Indonesia \\ ${ }^{*}$ Corresponding author. Email: jessica@fpsi.untar.ac.id
}

\begin{abstract}
The number of social media users continues to increase. In line with this, cyberbullying is something that needs to be considered by looking at the trigger factors. Psychological loneliness and emotional regulation are closely related to the cyberbullying perpetration. The aim of this research is to examine the role of psychological loneliness toward the emotional regulation cyberbullying perpetration among late adolescence in social media YouTube. This research involved 150 respondents, age 18 to 21 years old. The instruments were UCLA Loneliness Scale (version 3), Emotion Regulation Questionnaire, and Cyberbullying Offending Scale for screening. Retrieval of data using purposive sampling and the type of research used is non-experimental correlation research with quantitative methods. Hypothesis testing uses SPSS with regression analysis techniques between psychological loneliness and emotion regulation. The result is $\mathrm{t}(150)=-3.107, \mathrm{p}<0.05$, showed there is a significant role of the psychological loneliness toward the emotional regulation.
\end{abstract}

Keywords: psychological loneliness, emotion regulation, cyberbullying

\section{INTRODUCTION}

Global digital growth continues to show improvement, this growth clearly encourages the use of social media [13]. Global statistical data shows that by 2020 an estimated 3.6 billion people use social media [6]. In Indonesia, there were 160 million social media users in Indonesia January 2020 with an increase in social media use by 12 million $(8.1 \%)$ [14]. Late adolescence is the average age of most social media users in Indonesia [19], and according to theory aged 18-21 years who are included in the late adolescent development stage [22]. The popularity and development of social media sites have increased the activity of online bullying or cyberbullying behaviour [1]. Cyberbullying is involvement in the use of electronic communication technology to oppress others [16]. YouTube is the social media most frequently used by Indonesians with a proportion of $88 \%$ of the total number of social media users [14]. Cyberbullying on YouTube can be detected through comments on videos that discuss sensitive topics such as race, culture, intelligence, and sexuality, showing a detection indication of $66.7 \%$ [20]. Through a survey of more than 10,000 individuals, $66 \%$ were YouTube users, and $21 \%$ of that proportion experienced cyberbullying [8]. The emergence of cyberbullying can be associated with psychological loneliness, supported through previous research [2] [7] that psychological loneliness is associated with cyberbullying behaviour. As described, individuals who do cyberbully are dominated by those who lack the love, interest, and social support [2]. They feel lonely and use cyberbullying to vent their anger and feel a sense of power. Psychological loneliness is conceptualized as a negative emotion, in which individuals who maintain negative emotions or fail to maintain positive emotions tend to be more susceptible to experiencing negative influences, including loneliness [12]. Maintaining, increasing, or decreasing positive and negative emotions are things that individuals do while regulating their emotions [15].

Failure to maintain positive emotions or unable to regulate negative emotions can also increase the risk of individual involvement in cyberbullying [4]. Supported by research, that emotional regulation has a relationship with cyberbullying behaviour [18] [26]. Based on the results of previous research, psychological loneliness is closely related to cyberbullying and also emotional regulation are closely related to cyberbullying. Also refers to the phenomenon, knowing that psychological loneliness is related to how individuals regulate their emotions. Therefore, in this study, researchers are interested in knowing the role of psychological loneliness toward the emotional regulation, especially for late adolescents using social media YouTube

\subsection{Cyberbullying}

Cyberbullying can be defined as an aggressive and deliberate act carried out by a group or individual using a form of electronic contact, repeatedly and from time to time against victims who cannot easily defend themselves [23]. Cyberbullying can be explained as an act of harm and harm to others which is carried out through the use of computers, cell phones, or other electronic devices by sending messages or content that are hurtful and degrading to victims or by uploading them in various online forums that 
are widely visited by other user-existed work into two categories [11].

\subsubsection{Form of Cyberbullying}

There are seven forms of cyberbullying [3], namely: (a) Flaming refers to offensive, angry, and unfriendly interactions that are hurtful; (b) Harassment refers to a person's behaviour based on their status (gender, race, religion, disability, sexual orientation, or so on) that is against the law; (c) Denigration is the most common form of cyberbullying, which is degrading or disrespecting others by using technology; (d) Masquerading refers to the technique of an offender who uses the identity of another person (account, telephone number, etc.) to send messages that are rude or rude and remind them that the message is from someone else so that that person will be accused of behaviour; (e) Outery and Trickery, this form is a form of cooperation. In this form, the perpetrator usually lies to the victim by taking an oath to keep the information that has been given confidentially; (f) Social Exclusion is a deliberate act to isolate individuals in a social group; and (h) Cyberstalking, which is electronic stalking or surveillance (repeatedly threatening or harassing someone).

\subsubsection{Factors in Cyberbullying Engagement}

There are four factors [24], namely: First, traditional bullies have a higher risk of cyberbullying in the future. Second, rule-breaking behaviour is a form of negative behaviour such as smoking, consuming alcoholic beverages, hurting animals, or disturbing other people, where these behaviours have a double risk of engaging in cyberbullying. Third, individuals who have some form of antisocial behaviour in the real world have a high risk of being involved in cyberbullying, and lastly, online communication where the more time individuals spend communicating online, the higher the risk of involvement in cyberbullying.

\subsection{Psychological Loneliness}

Psychological loneliness is defined as an unpleasant experience, similar to other negative states of depression or loss and individuals reflect subjective perceptions of deficiencies in their network of social relationships both quantitatively (not enough friends) and qualitatively (periods of intimacy with others) [21]. The presence of physically important people in one's social environment is not a sufficient condition, in which a person needs to feel connected to others (spouses, family, and/or friends) so as not to feel lonely [5].

\subsubsection{Form of Psychological Loneliness}

Divided into two, namely emotional loneliness and social loneliness [21]. Emotional loneliness results from a lack of close and intimate attachments to other people. Individuals who have recently divorced, or ended romantic relationships should experience this form of loneliness. Emotional loneliness causes feelings of anxiety and isolation. Social loneliness is caused by a lack of social relationships where the person is part of a group of friends who share the same interests and activities. Individuals who have recently moved to a new social environment (for example, to a new city, job, or college) should experience this form of loneliness. Social loneliness is characterized by feelings of boredom, aimlessness, and marginalization.

\subsubsection{Psychological Loneliness Risk Factors}

There are three risk factors associated with psychological loneliness [17], namely: demographic, health, and socioenvironmental. The demographics associated with loneliness focus on six things: (1) Age, that age is most common in young adults between the ages of 18-25 years, stabilizes in middle adulthood, and peaks again at 65 years for older adults. (2) Gender, the fact that loneliness is more common in young and old women, how loneliness is measured is also important. (3) Marital status, states that unmarried individuals usually report feeling lonelier being married. Loneliness is most common among those who are widowed, followed by divorced and unmarried people. (4) Status of life, that is living alone with a higher level of loneliness. (5) Socio-economic status, states that lowerincome, lower education level, frequency of economic problems, and living in a poor neighbourhood are at a higher level of solitude. (6) The status of transmigrating to a country that is different from one's own country tends to increase feelings of loneliness.

Various health indicators are related to loneliness, which in the following section [17], examinations carried out in the last 14 years covered the factors responsible, found that these factors included physical health, mental health, cognitive health, and brain, biology, and genetics. Then, the socio-environment factor is divided into two, namely digital communication and the workplace. The increasing reliance on using digital tools to communicate with others, including smartphone applications, social media platforms, mobile messengers, and internet usage in general, is very attractive.

\subsection{Emotion Regulation}

Emotional regulation is the ability to experience and express or shape the emotions possessed by individuals in ways or through strategies that will make them better off [25]. During emotional regulation, people can increase, maintain, or decrease positive and negative emotions, therefore emotional regulation often occurs by involving changes in emotional responses [15]. There are many ways to manage unwanted and disruptive emotions, emotional regulation management has historically focused on (explicit) efforts to change the direction and intensity of emotional responses, but recently researchers have begun to describe effort and more spontaneously / automatically (implicit) as forms emotional emotions [10]. 


\subsubsection{Emotion Regulation Strategies}

There are two emotional regulation strategies, namely cognitive reappraisal and expressive suppression [9]. Cognitive reappraisal is defined as an individual act in which he tries to change the way he thinks about a situation to change its emotional impact. Individuals who use this strategy will respond to stressful situations by taking an optimistic attitude, reviewing what is considered stressful, and making efforts to improve a bad mood. Effectively, individuals with this strategy will express emotions more positively than those who rarely use this strategy. Socially, individuals with this strategy are more likely to share emotions (both positive and negative) with other people, and individuals have closer friendship relationships.

Expressive Suppression is defined as the action of an individual trying to express his behaviour or emotions. Individuals who use this strategy experience themselves as inauthentic, misinterpreting others about the true individual. Then, the individual responds to the stressful situation by covering up their inner feelings and holding back the outward display of their emotions. Individuals with this strategy lack a clear understanding of what they feel, are less successful in improving their moods and emotions as unpleasant or accept and reflect on things that make individuals feel bad. Positive influence, individual efforts to make individuals experience less positive emotional experiences and expressions. In terms of negative effects, individuals experience more negative emotions, including painful inauthentic feelings, individuals who rarely use this strategy.

\section{METHOD}

The type of research used is non-experimental correlation research with quantitative methods and the retrieval of data using purposive sampling,

\subsection{Participants}

Participants in this research were the late adolescents of cyberbullying perpetrators (who were determined based on the results of a screening using a cyberbullying offending scale measuring instrument) with an age range of 18-21 years who used and had YouTube social media accounts. In total there were 51 (34\%) men and 99 women (66\%).

\subsection{Measures}

\subsubsection{Psychological Loneliness}

Psychological Loneliness was measured using UCLA Loneliness Scale (Version 3) by Russell, D. (1996). This scale measured through 20 items, is designed to measure a person's subjective feelings and feelings of loneliness and feelings, by assessing each item on a 4-point numerical scale $(1=$ never, $2=$ sometimes, and $4=$ often $)$. Examples of items from this measuring instrument are: "How often do you feel alone?". There are 9 positive items and 11 negative items. Measuring the reliability of the UCLA Loneliness Scale (Version 3) and obtaining the results of Cronbach's Alpha $(\alpha)=0.910$. There is one item that is failed in the reliability test because the item has a corrected item-total correlation value $<0.2$.

\subsubsection{Emotion Regulation}

Emotion regulation was measured using Emotion Regulation Questionnaire (ERQ) by Gross and John (2003). This scale measured through 10 items, is designed to measure a person's use of 2 regulatory strategies, namely (1) cognitive reappraisal where a person tries to change the way he or she speaks the situation to change the emotional impact (e.g.: "When I am faced with a stressful situation, I make myself speak in a way which keeps me calm "), and (2) expressive suppression where a person tries to inhibit the expression of his behaviour or emotions (e.g.:" I keep my emotions to myself "). There are no negative items. Measuring the reliability of Emotion Regulation Questionnaire (ERQ) and obtaining the results of Cronbach's Alpha $(\alpha)=0.717$. There are no items that are failed in the reliability test because all items have a corrected item-total correlation value $>0.2$.

\subsubsection{Cyberbullying}

Cyberbullying was measured using Cyberbullying Offending Scale by Patchin and Hinduja (2015). This scale measured through 9 items, this instrument has 4 aspects, namely repetition, harm, intent (aim/purpose), and power imbalance. Example of items on this measuring instrument: "I write hurtful or mean comments to other people in cyberspace". The measuring instrument consists of 9 items using a Likert numeric scale of $5(1=$ never, $2=$ once, $3=$ very little, $4=$ several times, $5=$ often). There are no negative items. This measuring tool is used to assist researchers in screening participants whether participants are categorized as cyberbullying or not. If the participants' answers "never" to all items, then the participant is categorized as not a cyberbullying actor. Measuring the reliability of Cyberbullying Offending Scale and obtaining the results of Cronbach's Alpha $(\alpha)=0.940$. There are no items that are failed in the reliability test because all items have a corrected item-total correlation value $>0.2$.

\section{FINDINGS}

\subsection{Descriptive Results}

Based on data, in general, the participants' psychological loneliness was high $(\mathrm{M}=2.728$; $\mathrm{SD}=0.533$; Mean Hypothetic $=2.5)$. Then, in general the participants' emotion regulation was also high $(\mathrm{M}=5.054 ; \mathrm{SD}=0.798$ 
; Mean Hypothetic =4). The high result is because the mean value is greater than the hypothetical mean value.

\subsection{Data Analysis}

\subsubsection{Normality Test}

The normality test is carried out to determine whether the distribution of the data obtained is normal or not. The data distribution is stated to be normal, if the value (p) is greater than 0.05. Normality test for psychological loneliness shows $\mathrm{p}=0.096(>0.05)$, for emotion regulation shows $\mathrm{p}=$ 0.071 (>0.05). Therefore. it can be concluded that the data are normally distributed.

\subsubsection{Linearity Test}

The linearity test is carried out to see whether the variable relationship forms a straight-line relationship or not. The linearity test of psychological loneliness with emotion regulation showed $\mathrm{F}=1.203, \mathrm{p}=0.237$ (>0.05). So, it can be stated that there is a linear relationship between the two because the $(\mathrm{p})$ value is greater than 0.05 . Therefore, the relationship between the independent variable and the dependent variable is linear.

\subsubsection{Hypothesis Analysis}

Hypothesis analysis is carried out using the regression analysis. The results show that the role of psychological loneliness toward the emotional regulation is significant $\mathrm{t}$ $(150)=-3.107, \mathrm{p}=0.002(<0.05)$. R-Square $=0.061$. These means that psychological loneliness on adolescence cyberbullying perpetrator has $6.1 \%$ role to their emotional regulation.

Furthermore, the psychological loneliness variable correlation test was carried out with each strategy on the emotional regulation variable. The results of testing the correlation between the psychological loneliness variable and the cognitive reappraisal emotional regulation strategy shows that the psychological loneliness variable had no relationship with the cognitive reappraisal emotion regulation strategy. This is indicated by the value of $r(150)$ $=0.014$ and $\mathrm{p}$-value $=0.864>0.05$. Then, the results of testing the correlation of the psychological loneliness variable with the emotional expressive suppression regulation strategy, it is found that the psychological loneliness variable has a significant negative relationship with the expressive suppression emotion regulation strategy. This is indicated by the value of $\mathrm{r}(150)=-0.407$ and $\mathrm{p}$ value $=0.000(<0.05)$

\section{CONCLUSION}

Based on the results of research on the role of psychological loneliness toward the emotion regulation cyberbullying perpetration among late adolescence in social media
YouTube it is known that there is a significant, so the research hypothesis is accepted.

\section{DISCUSSION}

Based on the results, it can be seen that there is a negative effect of psychological loneliness on the emotional regulation of $6.1 \%$. This can be interpreted that when an individual's psychological loneliness is high, the individual will find it increasingly difficult to regulate their emotions. In this case, the cyberbullying perpetrator has high psychological loneliness, making it difficult to control emotions in cyberbullying (in this case such as: giving negative comments on other people's videos on YouTube). Supported by [12], said that if an individual feels lonely, then at that time their negative emotions will be more dominant. Where another researcher said that negative emotions can involve individuals in negative behavior (in this case the negative behavior is cyberbullying) [4].

The result of the analysis of the psychological loneliness variable are similar to the two previous research conducted by Al-Qudah [2] and Ghazali [6], said that cyberbullying perpetration have high psychological loneliness. However, the result of the analysis of the emotion regulation variabel shows a different result to the two previous research conducted by Mawardah and Adiyanti [18] and Yudes [26]. Researchers suspect that this is due to high emotional regulation which can be interpreted as two things: positive or negative, supported by the theory [15] said that during emotional regulation, individuals can increase, or decrease positive and negative emotions.

Expressive suppression in emotion regulation strategies has a significant negative relationship with psychological loneliness. This means that when psychological loneliness increases, expressive suppression decreases. Where the lonelier, the more expressed his emotions (such as: the more crying, anxiety and also fear [21]. However, cognitive reappraisal in emotion regulation strategies has no relationship with psychological loneliness. Researchers suspect that if the individual uses this strategy, the individual will express their emotions in a more positive way. It because the individual tries to change the way they think about the situation to change their emotional impact and they also has a more positive social environment. That statement is supported by the theory [9] said that individuals with this strategy will express emotions more positively. In social relations with other people, they have closer friendship relationships. In terms of well-being, individuals have fewer depressive symptoms, have greater self-esteem, and sufficient life satisfaction.

The limitation in this research is that the researcher does not clarify the criteria of the participants as "cyberbullying actors" to make it easier to control respondents due to the distribution of questionnaires via a google form. Then the researchers also did not deepen the factors related to cyberbullying to be discussed side by side with the two related variables. Besides, because it uses a cyberbullying offending scale measuring instrument that contains statement items related to negative behavior, researchers 
suspect that respondents who fill in do not fully answer according to what the truth is so that the data obtained is quite limited to be processed.

For next researchers can explore research related to the role of psychological loneliness and emotional regulation of cyberbullying perpetrators by conducting several tests to see this. The questionnaire items that the researcher used also had a high enough level of reliability and validity so that they could be used for similar research. Then, in further research, if you return to using this type of quantitative research it is quite effective to research similar research, but further research is suggested to use the mixed method, namely conducting quantitative and also qualitative research. This is suggested by researchers to obtain deeper information through qualitative methods, to produce and obtain more in-depth, precise, and more accurate information. In addition, for further information, psychological loneliness can be minimized by increasing the intensity of sharing stories or sharing thoughts to trusted friends. Emotion regulation can be minimized by trying not to express emotions directly in public.

\section{REFERENCES}

[1] Al-Garadi, M. A., Hussain, M. R., Khan, N., Murtaza, G., Nweke, H. F., Ali, I., Mujtaba, G., Chiroma, H., Khattak, H. A., \& Gani, A. (2019). Predicting cyberbullying on social media in the big data era using machine learning algorithms: Review of literature and open challenges. IEEE Access, 7, 70701-70718. https://doi.org/10.1109/access. 2019.2918354

[2] Al Qudah, M. F., Al-Barashdi, H. F., Hassan, E. M. A. H., Albursan, I. S., Heilat, M. Q., Bakhiet, S. F. A., \& AlKhader, M. A. (2019). Psychological security, psychological loneliness, and age as the predictors of cyberbullying among university students. Community Mental Health Journal. https://doi.org/10.1007/s10597-01900455-z

[3] Bauman, S. (2015). Types of Cyberbullying. Cyberbullying, $\quad$ 53-58. https://doi.org/10.1002/ 9781119221685.ch4

[4] Baroncelli, A., \& Ciucci, E. (2014). Unique effects of different components of trait emotional intelligence in traditional bullying and cyberbullying. Journal of Adolescence, 37(6), 807-815. https://doi.org/10.1016/j. adolescence.2014.05.009

[5] Cacioppo, S., Grippo, A. J., London, S., Goossens, L., \& Cacioppo, J. T. (2015). Loneliness: A clinical import and interventions. Perspectives on Psychological Science, 10(2), 238-249. https://doi.org/10.1177/1745691615570616

[6] Clement, J. (2020, July 15). Number of social network users worldwide from 2017 to 2025. Statista. https:// www.statista.com/statistics/278414/number-of-worldwidesocial-network-users/

[7] Ghazali, A. H. A., Samah, A. A., Omar, S. Z., Abdullah, H., Ahmad, A., \& Shaffrill, H. A. M. (2020). Predictors of cyberbullying among Malaysian youth. Journal of Cognitive Sciences and Human Development, 6(1), 67-80. https:// doi.og/10.33736/jcshd.1518.2020

[8] Gloerich, I. (2017, May 17). The dark side og YouTube: Cyberbullying 101. Network cultures. https:// networkcultures.org/online-self/2017/05/17/the-dark-sideof-youtube-cyberbullying-101/

[9] Gross, J. J., \& John, O. P. (2003). Individual differences in two emotion regulation processes: Implications for affect, relationships, and well-being. Journal of Personality and Social Psychology, 85(2), 348-362. https://doi.org/10.1037/ 0022-3514.85.2.348

[10] Gyurak, A., Gross, J. J., \& Etkin, A. (2011). Explicit and implicit emotion regulation: A dual-process framework. Cognition \& Emotion, 25(3), 400-412. https://doi.org/ $10.1080 / 02699931.2010 .544160$

[11] Hinduja, S., \& Patchin, J.W. (2008). Cyberbullying: An exploratory analysis of factors related to offending and victimization. Deviant Behavior, 29(2), 129-156. https:// doi.org/10.1080/01639620701457816

[12] Kearns, S. M., \& Creaven, A.-M. (2016). Individual differences in positive and negative emotion regulation: Which strategies explain variability in loneliness? Personality and Mental Health, 11(1), 64-74. https:// doi.org/10.1002/pmh.1363

[13] Kemp, S. (2019). Digital in 2019. We Are Social Inc. https://wearesocial.com/global-digital-report-2019

[14] Kemp, S. (2020, February 18). Digital 2020: Indonesia. Datareportal. https://datareportal.com/reports/digital-2020indonesia

[15] Koole, S. L. (2009). The psychology of emotion regulation: An integrative review. Cognition \& Emotion, 23(1), 4-41. https://doi.org/10.1080/02699930802619031

[16] Kowalski, R. M., Giumetti, G. W., Schroeder, A. N., \& Lattanner, M. R. (2014). Bullying in the digital age: A critical review and meta-analysis of cyberbullying research among youth. Psychological Bulletin, 140(4), 10731137. https://doi.org/10.1037/a0035618

[17] Lim, M. H., Eres, R., \& Vasan, S. (2020). Understanding loneliness in the twenty-first century: An update on correlates, risk factors, and potential solutions. Social Psychiatry and Psychiatric Epidemiology. https://doi.org/10.1007/s00127-020-01889-7 
[18] Mawardah, M., \& Adiyanti, M. G. (2014). Regulasi emosi dan kelompok teman sebaya pelaku cyberbullying. Jurnal Psikologi, 41(1), 60-73. https://journal.ugm.ac.id/ jpsi/article/view/6958/pdf_41

[19] Pertiwi, W. K. (2019, February 4). Separuh penduduk Indonesia sudah "melek" media sosial. Kompas. https:// tekno.kompas.com/read/2019/02/04/19140037/separuhpenduduk-indonesia-sudah-melek-mediasosial\#: :text= Pengguna $\% 20$ media\%20sosial $\% 20$ di $\% 20$ Indonesia $\% 20$ paling\%20banyak\%20berada\%20pada\%20rentang,wanita $\% 20$ dengan $\% 20$ persentase $\% 2015 \% 20$ persen.

[20] Reynolds, K., Kontostathis, A., \& Edwards, L. (2011). Using Machine Learning to Detect Cyberbullying. International Conference on Machine Learning and Applications and Workshops. 241-244. https://doi.org/10. 1109/icmla.2011.152

[21] Russell, D., Cutrona, C. E., Rose, J., \& Yurko, K. (1984). Social and emotional loneliness: An examination of Weiss's typology of loneliness. Journal of Personality and Social Psychology, 46(6), 1313-1321. https://doi.org/10. 1037/0022-3514.46.6.1313

[22] Santrock, J. W. (2011). Life-span development (13 ${ }^{\text {th }}$ ed.). McGraw-Hill.

[23] Smith, P. K., Mahdavi, J., Carvalho, M., Fisher, S., Russell, S., \& Tippett, N. (2008). Cyberbullying: its nature and impact in secondary school pupils. Journal of Child Psychology and Psychiatry, 49(4), 376-385. https://doi.org/ 10.1111/j.1469-7610.2007.01846.x

[24] Sticca, F., Ruggieri, S., Alsaker, F., \& Perren, S. (2012). Longitudinal risk factors for cyberbullying in adolescence. Journal of Community \& Applied Social Psychology, 23(1), 52-67. https://doi.org/10.1002/casp. 2136

[25] Wigati, M., Diponegoro, A. M., \& Bashori, K. (2020). Roles of empathy, emotion regulation and school climate against cyber bullying in high schools in merangin, Jambi. American Research Journal of Humanities \& Social Science, 3(8), 72-79. https://www.arjhss.com/

[26] Yudes, C., Rey, L., \& Extremera, N. (2020). Predictive factors of cyberbullying perpetration amongst spanish adolescents. International Journal of Environmental Research and Public Health, 17(11), 1-14. https://doi.org/ 10.3390/ijerph171139 